\title{
Addressing the Practice of Safety Management in Halal Industry - An Overview and A Step Towards Sustainable Cooperation
}

\author{
${ }^{1}$ Azizan Ramli, ${ }^{2}$ Mohd Ezuan Abdul Jalil \\ ${ }^{1}$ Faculty of Chemical and Natural Resources Engineering, University Malaysia Pahang, 26300, \\ Kuantan, Pahang \\ ${ }^{2}$ Faculty of Engineering Technology, University Malaysia Pahang, 26300, Kuantan, Pahang, \\ Malaysia \\ Iazra6935@yahoo.com
}

\begin{abstract}
Global demands of halal products are expected to increase in near future. Hence, Malaysia has taken proactive actions to realize its aspiration in becoming a champion of global halal hub. However, this development has also brought along impact on safety level for halal industry's workers and neighborhood. Thus, the purpose of this paper is to provide an overview of safety management in halal industry and obtains halal player's opinion towards cooperative safety management. The research method involved analysis on current state of safety management practice in halal industry and survey. These methods are not mutually exclusive approaches but they are complimentary. The results shown that both dominance (government-to-halal industry) and individual approaches (exclusively move as an individual) aim to establish mutual cooperation between authority and halal industry in fostering a safety culture. In addition, the findings also shown that the initial development of cooperative safety management is noteworthy but yet, this approach requires further in-depth study.
\end{abstract}

Index Terms- halal industry, safety management, cooperative approach

\section{INTRODUCTION}

According to the latest Global Islamic Economy Report, the global spending on halal products could rise $10.8 \%$ yearly until 2019 [1]. This trend will trigger the emergent of what so-called halal economy into global economy growth. The halal economy has become a new niche in global economy sectors that reach RM8.4 trillion annually [2]. The effect of this growth leads an increase in both production capacity of the existing halal industry and emergence of new halal players. Moreover, the number of new halal industry was also expected to grow at a rate of up to 300 industries a year starting in 2015 [3]. In Malaysia, the number of halal certified companies have aroused almost twice from 2011 to 2015 with an average of $25 \%$ increment per year [4]. Thus, Malaysia is working hardly to achieve its aspiration to become a global halal hub champion. Indeed, Halal industry development is auspicious as one of the Malaysia's key economic drivers. In addition, according to the achievement report issued by Malaysia's Ministry of International Trade and Industry (MITI), Malaysia halal export revenue has achieved RM42 billion in 2015 with approximate number of Small and Medium Enterprise (SME) exporters are 800 companies [4].

Malaysia's halal industry has undergone great transformation as described in Chapter 21: Halal Industry Development, Malaysia Third Industrial Development Master Plan or known by its acronym as IMP3 [5]. The governmental planning on halal industry development has been succeeded to materialize in partial. The increase of halal industry is proliferating throughout the country. This can been seen as Malaysian Government has successfully established more than 20 designated industrial area which are dedicated to the production of halal products and 15 of them are currently in operation [6]. Moreover, halal industry development also being catalyzed through the establishment of multiagency coordination which is in addition to the drafting of regulations, standards and guidelines for halal production activities. The overall operation of the halal ecosystem network in Malaysia as depicted in figure 1. Basically, the halal ecosystem network is built through four stimuli drivers that anchoring its operational structure; 1) Malaysia's halal standard and guidelines (i.e MS1500, MS2400, MS2424), 2) halal complimentary standards and guidelines (i.e HACCP, GMP), 3) halal related agencies/institutions (i.e JAKIM ${ }^{1}, \mathrm{HDC}^{2}$, $\mathrm{SIRIM}^{3}$ ), and 4) halal industry related legislations (i.e Trade

${ }^{1} \mathrm{JAKIM}$ is an acronym of Islamic Development Department, Malaysia

${ }^{2} \mathrm{HDC}$ is an acronym of Halal Industry Development Corporation, Malaysia 
Description Act 2011, Food Act 1983). These drivers are playing a vital role to ensure the sustainability of halal ecosystem as well as the integrity and assurance of halal products and its process management. Despite the existence of various mechanisms, halal industry is also seen to grow in a competitive global economy. Safety aspect of the workers and neighborhood is integral to the course. Indeed, the greater challenge of recent global economy makes internationally accepted safety compliance as one of the essential element for the competitiveness. In other words, it is commonly accepted that safety-compliance becomes one of the key determinants of firm competitiveness. Studies have also shown that creating a safe workplace seeks to provide cost savings for an organization to become stronger and more competitive [7]. Muñiz et al. [8] have also contended that performance is directly affected competitiveness through the implementation of safety management at the workplace. Thus, to ensure halal industry is prepared to cope with workplace's accident, the implementation of safety management is neither an option nor voluntary. This move is indeed in line with the needs to provide safer workplace as it is growing worldwide [9].

Benefits from the halal economy concomitant with increase of potential accident and lackadaisical attitude of safety culture. In other words, the increasingly halal global market might proportionate to the increased number of accident cases if safety conscious is in absence. The issues on the rights of workers as to be in safer workplace, safety of the people and neighborhood in the proximity become a primary concern of both government and industry. This substantive issue is no more to be treated as a less priority in any organization. Moreover, aspects of sustainable development of the halal industry is also an important feature in response to the will of the international community. In the context of social development, stronger safety management safeguards are needed to protect workers from workplace's accidents whether personal accidents or the disastrous one's. This is also a small part of the sustainable development's component that cannot be disregarded.

\footnotetext{
${ }^{3}$ SIRIM is an acronym of Standards and Industrial Research Institute of Malaysia
} 


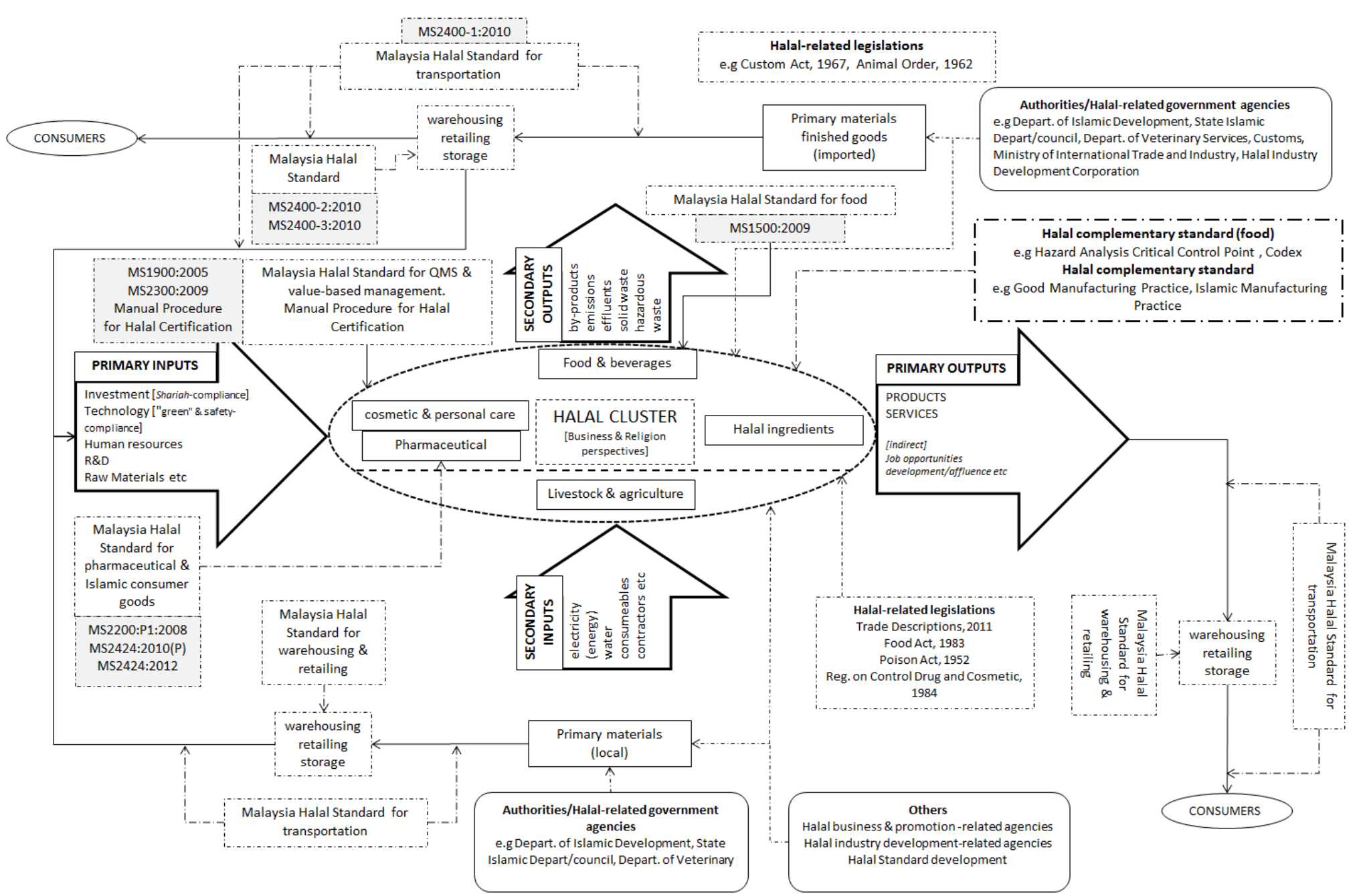

Figure 1: Malaysia's halal industry ecosystem network (modified from [6]) 
Furthermore, according to the International Labor Organization, it is expected that 500 million new jobs will be needed in the near future [10]. In Malaysia alone, employment in halal industry has increased from 206,000 in 2014 to 218,000 in 2015, with a difference of 12,000 in just a year [4]. This is a pre-indicator that showing the bright future of halal industry development for both at domestic and international levels. Besides, the sustainable development interlink three dimensional interaction: environment, economy, and social. The occupational safety and health management as a safeguard against accident and indeed it is part of social dimension of sustainable development as to ensure the welfare and wellbeing of workers $[11,12,13]$. Moreover, the right of workers at workplace has become an integral element of the new 2030 Agenda for Sustainable Development [14]. Thus, safety issue is also part of this process which requires an immediate attention, especially in the developing country like Malaysia.

Undoubtedly, the growth of industrial-based economy such as halal industry is clearly provide a positive impact in increasing the country's wealth and prosperity as to improve the welfare of the people. However, the emphasis on development sometimes drown out the needs of society, especially workers to live safer and healthier. Furthermore, the increasing diversity of the industrial sector in a country's economic growth has resulted in the birth of an increase in the diversity of products and processes [15]. It also led to increasingly complex industrial systems [16]. The issue of worker's safety and the safety of the surrounding communities become more challenging between a myriad of halal industrial sectors' development. Thus, industry is shouldering a responsibility to strengthen the industrial safety management matter and playing more active role in preventing and reducing the occurrence of potential accidents [17]. In addition, regardless of its scale of severity, the number of accidents occurred is not the only indicator to measure safety performance in any organization. The accident statistic is associated with reactive measurement or known as a lagging indicator. Hence, there should be more diverse indicators which could represent the comprehensive efforts done by all parties for both leading and lagging measurements. The selected indicators also should have an ability to predict and representing the shortcomings so that further improvement can be planned and executed $[18]$.

Although most of the halal industry are not categorized as a high-risk, but the existence of industries such as pharmaceuticals and manufacturing of halal ingredients (chemicals, oleo-chemicals and petrochemicals-based) incubate many unexpected things to happen. Furthermore, the historical disastrous accidents that ever occurred in the past are crystal-cleared evidence that herald an immediate attention. In fact, in the recent years many fatal accidents have also occurred in industries that are retrospectively considered as low risk [19]. Moreover, the workplace safety has come to the fore since future risks are more unpredictable due to technology advancement. Therefore, preventive measures should always be given an emphasis and priority even though to a relatively low risk industry such as halal industry.

Thus, this article discusses the current state of safety management activities within the context of Malaysia's industry in general and halal industry in particular. We also pursued an opinion from halal industry's representative with regards to cooperative safety management. Additionally, the objective is also to measure whether current safety management activities could herald a new era of further improvement by integrating and valuing the teaching of Islam. However, we have yet to go about developing this initiative nor solving the drawback because the main aim of this study is only to address the current state of safety management activities in Halal industry cluster and not arrive at the final solution to establish cooperative safety management initiative.

\section{METHODOLOGY}

The purpose of this paper is to provide information on the current state of safety management activities in halal industry. In order to address this matter, twofold analysis methods are conducted. These methods are not mutually exclusive approaches but they are complimentary. In general, there are two main secondary sources of data regarding occupational safety and health $(\mathrm{OSH})$ information in Malaysia; Social Security Organization of Malaysia (known by its acronym as PERKESO) and Malaysia's Department of Occupational Safety and Health (JKKP). Thus, the first phase involves a study on the reliable reports and documents issued by these agencies. Information from these two key 
agencies is of paramount importance to obtain an overview on the status quo of safety management activities in Malaysia. In addition, information on the latest status of OSH MP15's ${ }^{4}$ activities and progress was also reviewed. The current state of programs and activities undertaken at national level is important as a measure of general achievement, particularly in industry which focuses on the manufacturing of halal products.

The second method is field survey. This was done in order to obtain direct inputs from halal industry's respondents. The questionnaire was designed in such way to try to reveal the current practice of safety management behind the existing situation at Malaysia's halal industry, as far as safety is concerned. Survey targets are the representatives of various types of halal industries throughout Malaysia. All respondents are randomly selected from Halal Industry Directory, Malaysian Islamic Development Department representing all types of halal industry categories. However, the food products will be given a priority since it contribute more that $60 \%$ of the halal economy. The selected halal industries are those who are operating either in existing industrial areas or halaldesignated industrial areas (known as Halal Park). The survey questionnaire was divided into five parts and the first part seeks background information about the respondents. All questions in Part 2 to Part 4 confined to simple "yes", "no", and "not sure" category. However, Part 5 had five point-scale's Likert style rating questions: from strongly disagree (1) to strongly agree (5). In this part, the questionnaire was developed to obtain respondent's opinions of benefits of each variable pertaining to cooperative safety management. In details, the questionnaire was divided into five main sections; (1) general information-type and category of halal industry, (2) accident's experience, (3) safety management system, and (4) opinions on cooperative approach in safety management. However, to get information (4), HSM-RAI (Health and safety management's relative agreement importance index) formulation and level of benefits are used as proposed by Chileshe and Dzisi [20]. The HSM-RAI was calculated using the following formulas:

$$
\begin{aligned}
& \mathrm{HSM}=\sum_{a=1}^{5} W i / N \\
& \mathrm{RAI}=\left(\sum W i\right) / A X N
\end{aligned}
$$

$W i$ is representing the total score assigned by the halal industry's respondents, $\mathrm{N}$ is the total number of response (97 in this case), and A is the maximum value of 5 in Likert scale. The RAI result will then classified into three categories of level; Low (HSM 1.0 to $<3.0$ and RAI 0.2 to $<0.6$ ), Medium (HSM 3.0 to $<4.0$ and RAI 0.6 to $<0.8$ ), and High (HSM 4.0 to 5.0 and RAI 0.8 to 1.0 ).

\section{RESULT}

The survey was conducted between December 2013 and March 2015. The total of 428 questionnaires were sent either by postal mail with return envelope or by email, and finally resulting in a response rate of $23 \%$. Hassan et al. [21] have carried out the similar study pertaining to workplace accident in Malaysia. They managed to obtain the response rate of $7.4 \%$ and it still can be accepted. Thus, $23 \%$ response rate indeed is quiet encouraging and deemed more than adequate for the data analysis of this study.

The respondents are divided into five categories which are food/beverages, halal ingredients (oleochemicals, herbs, chemicals, and petrochemicals), pharmaceuticals, cosmetics, personal care products, and daily used products. The low response rate is initially expected since information on safety is still treated as confidential by most of the organizations. In other words, the relatively slow response from halal industries is due to the reluctance of companies to divulge information. In fact, it is not possible to obtain necessary safety information from industry due to confidentiality concern [22]. Thus, quiet a number of survey forms were purposely distributed to selected industries to ensure adequate feedback. The response rate was somewhat slower in the early stage. All respondents were then re-contacted through e-mail, phone or postal. At last, a total of 97 halal industries have responded (the total number

\footnotetext{
${ }^{4}$ Malaysia Occupational Safety and Health Master Plan 2011-2015.
} 
of respondent is based on $90 \%$ confidence level from 4,080 halal industry in Malaysia as listed in the Halal Industry Directory). The returned survey forms were made up of Small and Medium Enterprise, SME (65\%), Multi-national Company, MNC (27\%), Government-linked Company, GLC (7\%) and micro-scale halal industry (1\%). Of all halal product categories, food processing industry is the dominant and constitutes 54\%. Halal ingredients, cosmetics and personal cares product, and pharmaceuticals represented $22 \%, 10 \%$ and $9 \%$ of the total feedbacks respectively

In general, almost all respondents (97\%) agreed that the implementation of industrial safety management is important for business to sustain. This is because the studies have showed that business or industry that implement safety management system have performed financially better than those who not [7]. Furthermore, the impact of the disruption caused by accident can affect the business activity tangibly [23]. In other words, failure to implement safety preventive measures will potentially give a significant impact on the business ability to remain competitive, if accidents emerge.

\subsection{Accident trend}

The safety performance status is often measured by the number of reported accidents to the authority. Accident statistic is a reactive indicator which is generally being used to demonstrate the effectiveness of the prevention activities undertaken. However, to date, accident statistics reported by both JKKP and PERKESO do not segregate the accident cases with accordance to whether halal industry or not. Therefore, accidents data in this study was taken and digested from the relevant sectors of industry which are by nature manufacture the halal-focused products. The data is mainly based as far as possible on official statistic issued by PERKESO. These aforementioned halal-focused sectors are specialty food/beverages (non-alcoholic or non-pork), pharmaceuticals, halal ingredients (oleochemical, chemical, petrochemical, and herbs), cosmetics and personal cares product, and daily used products. In general, the statistics showed that the number of industrial accidents between 2008 and 2013 is fluctuating both in absolute term (excluding number of accidents in relation to occupational disease). Looking back over a same period of time, the number of workplace accidents in halalfocused industry showed a clear downward trend within first few years but the pattern start to fluctuate afterward. In essence, the percentage of accidents occurred in halal-focused industry from 2008 to 2013 constituted $8.4 \%$ from the total number of accidents reported. The same number of cases covered approximately $17 \%$ of the total cases in the relevant sectors. Even though percentage-wise is relatively low but considering future huge demands for halal products and technology advancement, safety issue is becoming more critical than may seem, if effective and comprehensive prevention measures are paid less attention.

Moreover, accident is unexpected and unpredictable event. It can happen at any time and sometimes without alerting any signs. Thus, the concern for safety measures indeed ought to be given a priority. Although there might be a decrease in the number of accidents but in reality, accident is still keep on happening [24] including in a company that has a good safety management system [25]. In addition, the safety performance of an organization should not merely rely on the officially reported accident cases. According to the study by Probst et al. [26], the actual accident cases in most of organization are much higher, in contrast to the cases that being reported to the authority. However, He et al. [27] contended that despite the officially reported data may not reflect the actual information about the accident, but it can be used to get a rough idea. Understanding this fact, Ministry of Human Resources (MHR), spearheaded by JKKP is conducting a study to improve accident data collection process. However, the progress is still at the draft stage and the newly approach on data collection activity is yet to be implemented. Furthermore, reliance solely on accident statistics (lagging/reactive indicator) not really reflect the actual overall safety performance of an organization. This is because the dependency on the accident statistics, especially SMEs are still less effective for measuring the level of safety in an organization [28]. Thus, the development of more diverse and comprehensive indicators are unignorably needed.

The work-related accidents are not only disrupt productivity and effect organization reputation but also can cause financial implication. The data showed that benefit payments to the accident's victims of halal-focused industry has shown an upward trend at the rate of nearly 16\% in 2013 compared to 2009 (this amount is subject to investigation or judicial result over time). This benefit payments are 
only to cover compensation for the cases of Temporary Disablement Benefit (TDB), Permanent Disablement Benefit (PD), and Dependents' Benefits (DB). Moreover, the average amount of expenses for TDB, PD, and DB cases from 2009 to 2013 are 4589, 999, and 67 respectively. However, the total expenses inclusive of medical, pension, allowances, funeral and rehabilitation has reached RM162 million in 2013, a difference of RM39 million as compared to 2009. The overall cost showed an increase of over 30\% compared to 2009.

In addition to official statistical data issued by PERKESO and JKKP, information regarding to accident experience was also collected from the halal industry's respondents. However, this data is not representing the number of accident cases but the information on whether they have had ever experienced any minor or major accidents so far. Data on accident experience is chosen as most industries still thinks that detailed information about the number of accident cases is an internal matter and confidential. Le Bot [29] contended that confidentiality will start to emerge when people noticed that they are being monitored. This argument was supported by Basta et al. [30] as they said that most industries take precautionary action in sharing industrial information. They added that this attitude is due to deep anxiety about abuse of information given. Moreover, for various reasons, some industries refuse to disclose their company name when accident information is publicized [31]. Therefore, to minimize these concerns, halal industry respondents who involved in this survey were only being asked whether they have ever experienced workplace accidents in the past five years so as since the establishment of the company. The accident experience category then are divided into four; large or small-scale accidents, fatality, loss of property, and hazardous chemical spills. The five-year data showed that almost all MNCs and GLCs, and approximate 50\% of SME's have experienced cases of minor accidents. Within the same period, about 23\% of MNCs and 14\% of GLCs had experienced major accident cases. In contrast, this involved less than $10 \%$ of SME's. Unlike MNC and SME's, large number of GLC ever faced loss of property resulting from accident. In addition to five years accident experience, experience in the case of major hazardous chemical spills, explosions, fires, fatality and huge loss of property were also reviewed. However, these kinds of disastrous accidents are rarely occur [32,33,34]. Thus, the information collected is based on halal industry's experience since its establishment. Explosions, fires and spills of hazardous chemicals have been suffered 25\%, 7\%, and $12 \%$ by each of respondents from various categories of halal industry. Fires was the highest case (56\%), followed by spills of hazardous chemicals (28\%) and explosion (16\%). In both cases of property loss and fatality, $11 \%$ of halal industry's respondents have ever experienced it since their establishment. The information obtained is an organization's internal information. Internal reporting accidents usually used for management reference to develop the long-term and short-term plans. A recent survey showed that most of the halal industry implemented recording system on accident cases $(82 \%)$. However, there are still some halal industries, especially SMEs do not practice a proper system of accident's recording (24\%). Although they exist in a small quantity but in the long run, the long term implications is something that need to be taken in a very serious consideration.

\subsection{Ongoing program and activities}

Function and structure of multifarious parties to address safety issues at workplace is undoubtedly important. In Malaysia, there are eight organizational structure and external mechanisms involved and halal industry is also part of the subject in need of such support. Collaboration between government, industry, NGO's and diverse organizations is essential for the sustenance of safer working environment especially in the halal industry cluster. This coincided with the expansion and development of halal industry clusters as a new driver for Malaysia's economy. Indeed, the structure function of those existing organizations and mechanisms are looking into ways of invigorating overall occupational safety performance and introducing various techniques to circumvent safety measures.

In general, issue pertaining to workplace safety is under jurisdiction of two main agencies, namely JKKP and PERKESO. In addition to accident's recording, compensation and rehabilitation, PERKESO continually provides financial grants for NGO's such as the Malaysian Society for Occupational Safety and Health (MSOSH), Malaysian Trades Union Congress (MTUC) and the Malaysian Employers Federation (MEF), to name a few, to organize various OSH programs. Amongst those programs are conferences, seminars and discussions, both at the level of national or 
international. These programs are held from time to time to ensure that the issue of workplace safety is always in the limelight. "Return-to-Work" Program which was introduced in 2007, is one of the postaccident rehabilitation program. This program aims to help accident's victims in increasing their physical and mental capacity to return to work in a confident and fast manner. In addition, through cooperation with JKKP, PERKESO has also implemented what so-called the "OSH Compliance Support for SME". This program aims to supervise and provide advisory services related to safety at work to SME's. Halal industry which mainly dominated by more than $80 \%$ of SMEs had received the valuable benefits from this program. However, this program does not involve all halal's SME because participants are selected based on the recommendation by either employer or employee's associations. This means that only some of the halal's SME eligible to join the program.

In particular, the role of PERKESO is more focused on the issue of compensation and rehabilitation, as well as campaigns and promotions. Agency that play a vital role as an enforcer and coordinator is JKKP. To date, JKKP has been implementing variety of programs and activities that cover all categories of industry and organization including halal industry. In 2010, the Five-Year Master Plan for occupational safety and health (known as OSH MP15) has been developed in order to realize the goal to improve the level of safety at the workplace. Additionally, in OSH MP 2020 the emphasis was given to strengthen the safety culture amongst members in an organization. According to JKKP's annual report, the main focus will be given to the program pertaining to legal requirement, compliance and enforcement. These issues are crucial as most organizations and industry, especially SMEs, which is also main players of halal industry are less sensitive. This occurs because SMEs often treat issues relating to safety with less priority [35] and tend to pay less attention [36]. The findings of the survey also showed that more than $20 \%$ of SMEs gave no attention to the legal requirements. It involves $28 \%$ of SMEs for OSHA ${ }^{5}$ 1994, 25\% for FMA ${ }^{6}$, and $22 \%$ for other relevant acts. The above result shown that most of them are unsure about the compliance of these acts in their business activities.

Furthermore, government has been carrying out the study on the effectiveness of the existing legislations since 2012. Most of the halal industry's respondents $(76 \%)$ also agreed on the need to review and strengthen the existing legislative system. In addition, $17 \%$ of halal industry's respondents believes that existing legislations are less effective while 23\% of them not sure. Although the need for amendment is important but until now the review is still at the stage of report preparation and it has not yet been discussed thoroughly. Moreover, suggestion for a new legislation is also under government's consideration but the status is still undecided.

The survey findings pertaining to the current state of safety management practice in halal industry is tabulated in Table 1. The factor/element that being assessed above $70 \%$ indicates good condition and considered as "adequate" [37,38]. Approximately $46 \%$ of halal industry's respondents implement the entire basic elements of safety management in an organized manner. However, this does not take into account the off-site emergency preparedness plan since it depends on the level of risk in respect of the activities. In addition, this requirement is not a mandatory, as some halal industries are not in the category of high-risk which subject to CIMAH regulation ${ }^{7}$. However, most of halal industry's respondents have shown their attempt to implement some of the basic elements of safety management system. This attempt indicates that their concern and awareness on safety issue is increasing. Moreover, the finding also showed that approximate 47\% (45 companies) of halal industry's respondents have implemented safety management system in a systematic way and well-organized.

\footnotetext{
${ }^{5}$ OSHA is Occupational Safety and Health Act

${ }^{6}$ FMA is Factories and Machineries Act

${ }^{7} \mathrm{CIMAH}$ is Control of Industrial Major Accident Hazard Regulation
} 
Table 1: Implementation of basic elements of safety management system (based on Malaysia Standard MS1722 guideline).

\begin{tabular}{|c|c|c|c|c|}
\hline & Items & $\begin{array}{r}\text { Yes } \\
(\%)\end{array}$ & $\begin{array}{l}\text { No } \\
(\%)\end{array}$ & $\begin{array}{r}\text { Not sure } \\
(\%)\end{array}$ \\
\hline \multicolumn{5}{|c|}{ POLICY } \\
\hline 1 & $\begin{array}{l}\text { Did your company or factory establish the safety policy and convey to employees, contractors } \\
\text { and relevant stakeholders? }\end{array}$ & 91.8 & 4.1 & 4.1 \\
\hline 2 & $\begin{array}{l}\text { Are participation of employees in developing and reviewing safety policy, safety activities, } \\
\text { and procedures encouraged? }\end{array}$ & 86.6 & 6.2 & 7.2 \\
\hline \multicolumn{5}{|c|}{ ORGANIZING } \\
\hline 3 & Are roles and responsibilities of employees with regards to safety matter clearly described and conveyed? & 89.7 & 5.2 & 5.2 \\
\hline 4 & $\begin{array}{l}\text { Is there a system for safety induction to all categories of employees including contractors and visitors?- } \\
\text { awareness, competency program and competency assessment? }\end{array}$ & 79.4 & 10.3 & 10.3 \\
\hline 5 & $\begin{array}{l}\text { Did your company or factory establish the standards and procedure for safety management practice? } \\
\text { (including OSH manual, engineering practices, operational procedures and work instructions) }\end{array}$ & 78.4 & 9.3 & 12.4 \\
\hline 6 & $\begin{array}{l}\text { Is there a proper communication system to disseminate safety related information across } \\
\text { organization (internal communication)? }\end{array}$ & 82.5 & 6.2 & 11.3 \\
\hline 7 & $\begin{array}{l}\text { Is there a communication mechanism to receive, document and respond to relevant communication } \\
\text { from external interested parties such as neighboring community and authorities. }\end{array}$ & 60.8 & 14.4 & 24.7 \\
\hline
\end{tabular}




\section{PLANNING \& IMPLEMENTATION}

8 Did your company or factory develop and document safety objectives and its documented plan strategy?

$9 \quad$ Are there systematic procedures for hazard identification, risk assessment and risk control?

10 Did your company or factory establish an adequate on-site emergency preparedness plan

11 Did your company or factory establish an adequate off-site emergency preparedness plan

12 Did your company or factory take an appropriate steps prior to the introduction of changes, both internal and external (modification, new process, new legislation etc)

13 Is there a comprehensive system for incidents and near-misses management (reporting, investigations, corrective and preventive actions)?

\section{EVALUATION}

14 Is there a system in place for monitoring and measuring the effectiveness of the safety management system?

15 Is formal assessment of potential human error conducted?

\section{ACTION FOR IMPROVEMENT}

16 Is there a system to issue corrective actions and preventive actions to prevent recurrences of non-conformances to safety requirement?

17 Is there a system for preventive maintenance with condition-based monitoring of equipment 


\subsection{Moving towards cooperative safety management.}

In this section, we present the assessment result with regards to the benefits of cooperative safety management from the viewpoints of halal industry's respondents. Table 2 shows the descriptive statistics presenting the levels of the perceived benefits of cooperative approach in safety management. The overall finding showed a positive tendency towards the establishment of cooperative approach in safety management. The overall weightage has shown very significant benefits that cooperative approach can offer. In essence, these benefits have HSM values between 4.000 (unique integration on "know-how" and capabilities within halal industrial park) and 4.443 (safety is not about confidentiality but is a sharing of care). The result also showed that all of six advocated benefits were perceived to be high range.

Table 2: Benefits of cooperative safety management

\begin{tabular}{lccc}
\hline \multicolumn{1}{c}{ Perceived benefits } & Rank & $\begin{array}{c}\text { HSM- } \\
\text { RAI }\end{array}$ & $\begin{array}{c}\text { HSM } \\
\text { Level }\end{array}$ \\
\hline $\begin{array}{l}\text { "Safety" is not about "confidentiality" but it is a sharing of } \\
\text { care and industry may need to cooperate each other towards } \\
\text { safer workplace environment. }\end{array}$ & 1 & 0.889 & High \\
$\begin{array}{l}\text { Future technological hazards are becoming more complex } \\
\text { and unpredictable. Thus, establishment of cooperative } \\
\text { relationship is promising and noteworthy. }\end{array}$ & 4 & 0.823 & High \\
$\begin{array}{l}\text { Existence of diverse operations and processes, cooperative } \\
\text { approach might be needed. }\end{array}$ & 5 & 0.804 & High \\
$\begin{array}{l}\text { The cooperation on safety management is a synergic } \\
\text { approach for better industrial safety improvement }\end{array}$ & 2 & 0.841 & High \\
$\begin{array}{l}\text { Cooperation offers an unique integration of know-how } \\
\text { and capabilities within halal industrial park (e.g safety- } \\
\text { related knowledge from difference halal industries) }\end{array}$ & 6 & 0.800 & High \\
$\begin{array}{l}\text { This initiative will also help SME's (main players in Halal } \\
\text { industry) in enhancing their safety management performance. }\end{array}$ & 3 & 0.827 & High
\end{tabular}


The safety matter should not be treated as confidential and the initiative to develop mutual cooperation amongst members of the halal industry cluster is noteworthy. In other words, the cooperative approach seeks to increase the level of safety management practice in a synergistic way. The potential multifidus effects in the form of expertise, knowledge and resources could help especially halal's SMEs to improve the level of workplace safety at their premise. Furthermore, risk of future technology is difficult to predict due to existence of advanced operations and complex processes. Therefore, cooperation is capable to offer a unique integration on "know-how" and as a result, able to increase the safety capacity in halal industrial park. In conclusion, the inference to be drawn is that cooperative safety management has initially attracted widespread interest from halal industry players. However, the survey showed only $61 \%$ of halal industry's respondents or 59 halal companies have established a cooperation with other parties on issues relating to safety management (Figure 2 ). Of this, having the cooperation with government agencies $(55 \%)$ is the most especially with regards to advisory and legal issues. In addition, at approximate $28 \%$ of them have a collaborative relationship with professional bodies and NGO's. Only a small number have a relationship with other industries (10\% or 16 companies only) and local communities $(6 \%)$. However, none of the respondents have a relationship with higher education institutions for the purpose of consultation or R\&D. In general view, despite the agreement to all benefits, cooperation with other parties particularly with other industries is not yet becoming a common practice among halal players.

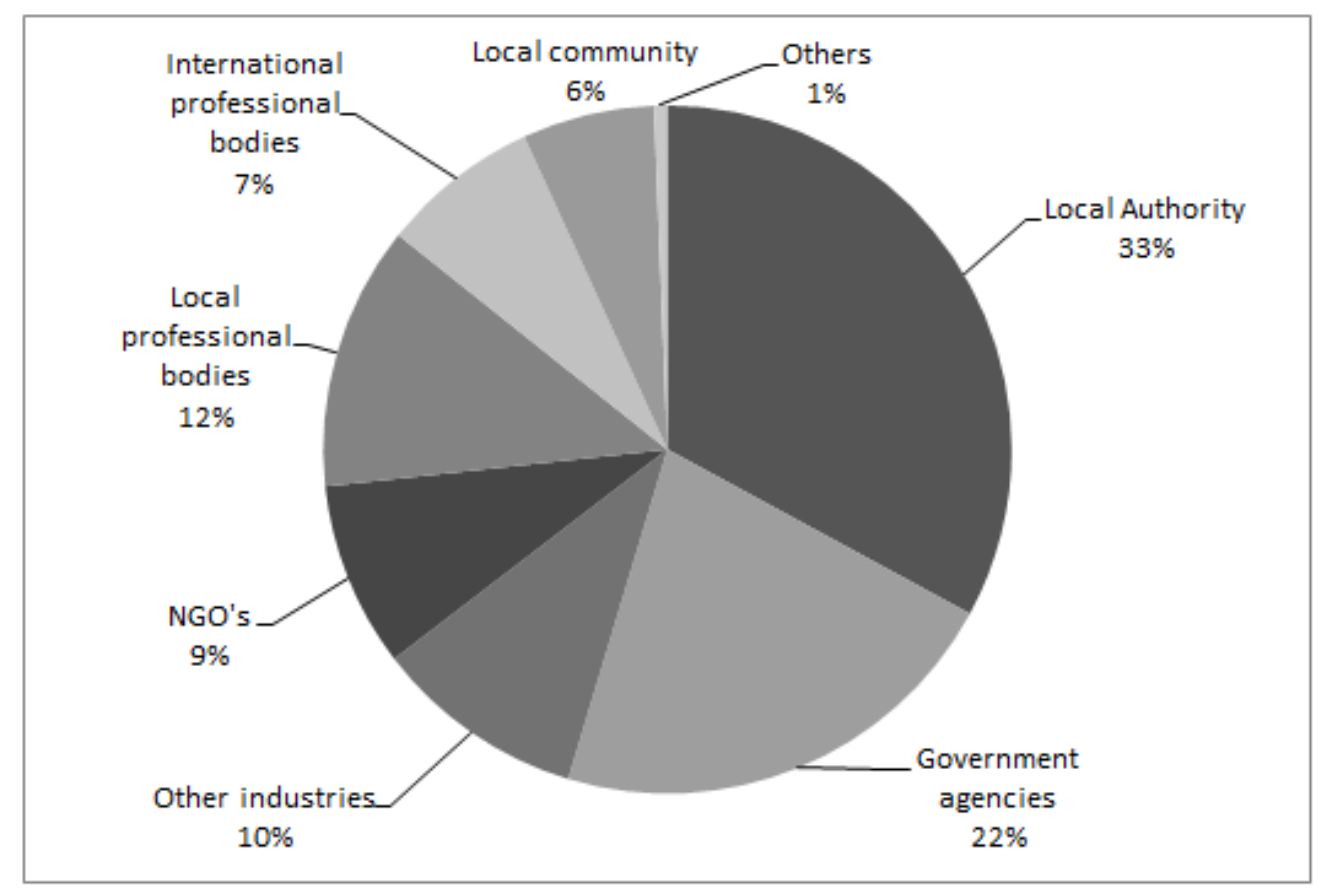

Figure 2: Current cooperation network in safety management among halal industry's respondents

In summation, the study showed that activities done by the authority and halal industry can be classified into a number of interrelated factors. These factors are institution (government agencies, academic), organization (halal industry), legislation, technology and finance (source). The emphasis on the implementation of safety management through the role of 
government agencies and the industry has also been outlined in the OSH MP15. The main aspects to be emphasized are the empowerment of industry (halal) and enhancement of safety culture. However, the process will be laborious and it involves a variety of factors in complexity to create an acceptable and safe workplace environment. Additionally, of all the halal industry's respondents, they indeed agreed that through cooperation, industry will gain more benefits in term of resources, competency, knowledge sharing, and mutual expertise assistance. However, even though this approach is intriguing and almost all of halal industry's respondents have come into consensus but it is not straightforward.

\section{CONCLUDING REMARKS}

To date, both dominance and individual approaches aim to establish mutual cooperation between authority and halal industry in fostering a safety culture. The cooperation amongst community of halal industries is yet a common practice. However, with an accelerating advanced technology, lack of knowledge and expertise, and financial constraints especially among halal SME's, the cooperative relationship may offer an alternative to cope with such deficiencies. To certain extend, current safety management practice may need to be further improved that go beyond their respective organization. The halal industry players should be ready to open their exclusiveness and partake into cooperation.

\section{REFERENCES}

[1] Trade Arabia, "Business News Information", Trade Arabia, 2016, http://tradearabia.com/news/IND_299715.html, accessed 19 July 2016

[2] World Halal Summit, 2015 http://www.worldhalalcouncil.com/world-halal-summit-2015.html, accessed 03 January 2016

[3] Salama, "Halal-industry-export-surplus-to-grow;MITI”,2015, http://halalfocus.net/malaysia-miti-expects-2015-halal-industry-export-surplus-to-grow/, accessed 15 July 2015.

[4] Mustapa M., "Status of the halal industry", Ministry of International Trade and Industry, 2016

http://www.mihas.com.my/wp-content/uploads/2016/02/WHW-2016-Status-of-theHalal-Industry.pdf, accessed 02 February 2016.

[5] IMP3, "Chapter 21: Halal Industry Development", Malaysian Third Industrial Master Plan 2006-2020, 2006,

http://www.miti.gov.my/miti/resources/auto\%20download\%20images/557f968c24904.p df, accessed 12 August 2014.

[6] Azizan R., Mazlin M., Badhrulhisham A.A., \& Nor Azman N., "The cooperative approach in managing safety issues for Halal industrial parks in Malaysia : embracing opportunity”, Progress in Industrial Ecology. 4(8) 295-318, 2014.

[7] Edwin F.J., "Safety Is Good Business", American Society of Safety Engineer. May 5658, 2008.

[8] Muñiz B.F., Péon J.M.M., \& Ordáz C.J., "Relation between occupational safety and firm performance", Safety Science. 47 980-991, 2009.

[9] Boustras G., Bratskas R., Tokakis V., \& Efstathiades A., "Safety awareness of practitioners in the Cypriot manufacturing sector", Journal of Engineering, Design and Technology. 1(9) 19-31, 2011. 
[10] ILO, "Economic and social development", International Labour Organisation, 2014, http://www.ilo.org/global/topics/economic-and-social-development/sustainabledevelopment/lang--en/index.htm, accessed 23 October 2015.

[11] Guoyou Q., Saixing Z., Haitao Y., \& Han L., "ISO and OHSAS certifications. How stakeholders affect corporate decisions on sustainability", Management Decision. 10(51) 1983-2005, 2013.

[12] Kwesi A-T., "Occupational Health and Safety and Sustainable Development in Ghana", International Journal of Business Administration. 2(4) 74-78, 2013.

[13] Zohreh M., \& Napsiah I., "The Relationship between Occupational Safety, Health, and Environment, and Sustainable Development: A Review and Critique", International Journal of Innovation, Management and Technology. 3(5) 198-202, 2014.

[14] ILO, "Decent work and sustainable development", International Labour Organisation, 2016, http://www.ilo.org/global/topics/decent-work/lang--en/index.htm, accessed 04 May 2016.

[15] Reniers G.L.L., \& Amyotte P., "Prevention in the chemical and process industries: Future directions", Journal of Loss Prevention in the Process Industries. 1(25) 227-231, 2012.

[16] Salvi O., Merad M., \& Rodrigues N., "Toward an integrative approach of the industrial risk management process in France", Journal of Loss Prevention in the Process Industries. 4-6(18) 414-422, 2005.

[17] Chan K.L., \& Chan A.H.S., "Understanding industrial safety signs : implications for occupational safety management", Industrial Management \& Data Systems. 9(111) 1481-1510, 2011.

[18] Manuele B.F.A., "A call for a new focus on their prevention all fatalities, all Occupations", American Society of Safety Engineers. December 32-39, 2008.

[19] Time, anonymous 'Occupational hazards the worst industrial disasters of 2013', Time, 2013, http://world.time.com/2013/06/05/occupational-hazards-the-worst-industrial-disastersof-2013/, accessed 10 May 2015.

[20] Chileshe N., \& Dzisi E., "Benefits and barriers of construction health and safety management (HSM) Perceptions of practitioners within design organizations", Journal of Engineering, Design and Technology. 2(10) 276-298, 2012.

[21] Hassan A., Nor Azimah C.A., \& Chandrakantan S., "Management practice in safety culture and its influence on workplace injury-An industrial study in Malaysia", Disaster Prevention and Management. 5(18) 470-77, 2009.

[22] Reniers G.L.L., "An external domino effects investment approach to improve crossplant safety within chemical clusters", Journal of Hazardous Material. 1-3(177) 167-74, 2010.

[23] Khakzad N., Khan F., \& Amyotte P., "Dynamic safety analysis of process systems by mapping bow-tie into Bayesian network", Process Safety and Environmental Protection. 1-2(91) 46-53, 2013.

[24] Rozaimah, Z., "Undang-undang keselamatan dan kesihatan pekerjaan (Akta 514): Pelaksanaan dan keberkesanan dalam mengawal kemalangan industri", Universiti Kebangsaan Malaysia: Master Dissertation, 2006

[25] Faridah I., Ahmad Ezanee H., Wan Zuriea W.I., Hikmah K., \& Zarita A.B., "Behaviour Based Approach for Quality and Safety Environment Improvement: Malaysian Experience in the Oil and Gas Industry", Procedia - Social and Behaviour Science, 35 86-594, 2012. 
[26] Probst T.M., Brubaker T.L., \& Barsotti A., "Organizational Injury Rate Underreporting: The Moderating Effect of Organizational Safety Climate", Journal of Applied Psychology. 5(93) 1147-1154, 2008.

[27] He G., Zhang L., Lu Y., \& Arthur P.J.M., "Managing major chemical accidents in China: towards effective risk information", Journal of Hazardous Materials. 1-3(187) 171-81, 2011.

[28] Duijm N.J., Fiévez C., Gerbec M., Haupmanns U., \& Konstandinidou M., "Management of health, safety and environment in process industry", Safety Science. 6(46) 908-920, 2008.

[29] Le Bot P., "Human reliability data, human error and accident models-illustration through the Three Mile Island accident analysis", Reliability Engineering and System Safety. 2(83) 153-167, 2004.

[30] Basta C., Neuvel J.M.M., Zlatanova S., \& Ale B., "Risk-maps informing land-use planning processes A survey on the Netherlands and the United Kingdom recent developments", Journal of Hazardous Materials. 1-2(145) 241-249, 2007.

[31] Sepeda A.L., "Lessons learned from process incident databases and the process safety incident database (PSID) approach sponsored by the Center for Chemical Process Safety", Journal of Hazardous Materials. 1-2(130) 9-14, 2006.

[32] Creedy G.D., "Quantitative risk assessment: How realistic are those frequency assumptions?, Journal of Loss Prevention in the Process Industries". 3(24) 203-207, 2011.

[33] Ibitayo O.O., Mushkatel A., \& Pijawka K.D., "Social and political amplification of technological hazards. The case of the PEPCON explosion", Journal of Hazardous Materials. 1-3(114) 15-25, 2004.

[34] Murray V., \& Goodfellow F., "Leading Article Mass casualty chemical incidentstowards guidance for public health management", Public Health. 116 2-14, 2002.

[35] Chan A.H.S., Kwok W.Y., \& Duffy V.G., "Using AHP for determining priority in a safety management system", Industrial Management \& Data Systems. 5(104) 430-445, 2004.

[36] Hasle P., Jørgen L.H., Kallehave T., Klitgaard C., \& Andersen T.R., "The working environment in small firms: Responses from owner-managers", International Small Business Journal. 1-18, 2011.

[37] Che Hassan C.R., Basha O.J., \& Hanafi W.H., "Perception of building construction workers towards safety, health and environment", Journal of Engineering Science and Technology. 3(2) 271-279, 2007.

[38] Rumaizah R., Zailina H., Ismi A.I., Lin N., \& Rusli N., “The Implications of a Health Promotion Program on the Knowledge and Practice of Automotive Workers Exposed To Solvent", American Journal of Applied Sciences. 5(7) 661-668, 2010. 